\title{
A hemoglobin-based oxygen carrier sensitized Cisplatin based chemotherapy in hepatocellular carcinoma
}

\author{
Xiang $\mathbf{Q i}^{1}$, Bing L. Wong ${ }^{3}$, Sze Hang Lau ${ }^{3}$, Kevin Tak-Pan Ng${ }^{1}$, Sui Yi Kwok ${ }^{3}$, Chris \\ Kin-Wai Sun ${ }^{3}$, Fei Chuen Tzang ${ }^{3}$, Yan Shao ${ }^{1}$, Chang Xian Li ${ }^{1}$, Wei Geng ${ }^{1}$, Chang \\ Chun Ling ${ }^{1}$, Yuen Yuen Ma ${ }^{1}$, Xiao Bing Liu ${ }^{1}$, Hui Liu ${ }^{1}$, Jiang Liu ${ }^{1}$, Wai Ho Yeung ${ }^{1}$, \\ Chung Mau Lo ${ }^{1,2}$ and Kwan Man ${ }^{1,2}$ \\ ${ }^{1}$ Department of Surgery, The University of Hong Kong, Hong Kong, China \\ ${ }^{2}$ Collaborative Innovation Center for Diagnosis and Treatment of Infectious Diseases, Hangzhou, China \\ ${ }^{3}$ New $\beta$ Innovation Limited, 18/F Chevalier Commercial Centre, Hong Kong, China \\ Correspondence to: Kwan Man, email: kwanman@hku.hk \\ Keywords: hemoglobin-based oxygen carrier, chemoresistance, HCC, Cisplatin, intravital imaging \\ Received: April 04, $2017 \quad$ Accepted: May 11, $2017 \quad$ Published: July 28, 2017 \\ Copyright: Qi et al. This is an open-access article distributed under the terms of the Creative Commons Attribution License 3.0 \\ (CC BY 3.0), which permits unrestricted use, distribution, and reproduction in any medium, provided the original author and source \\ are credited.
}

\section{ABSTRACT}

Background and Objective: Our previous study showed that liver graft injury not only promotes tumor recurrence, but also induces chemoresistance in recurrent HCC after liver transplantation. Recently, we found that the hemoglobin-based oxygen carrier"YQ23" significantly ameliorates hepatic IR injury and prevent tumor recurrence. Here, we intended to explore the novel therapeutic strategy using oxygen carrier "YQ23"to sensitize chemotherapy in HCC.

Methods: To investigate the role of YQ23 combined with Cisplatin, the proliferation of HCC cells was examined under combined treatment by MTT and colony formation. To explore the effect of YQ23 on sensitization of Cisplatin based chemotherapy, the orthotopic liver cancer model was established. To characterize the delivery of YQ23 in tumor tissue, the intravital imaging system was applied for longitudinal observation in ectopic liver cancer model. The distribution of YQ23 was examined by IVIS spectrum.

Results: YQ23 significantly suppressed the proliferation of HCC cells under Cisplatin treatment in a dose and time dependent manner. Moreover, YQ23 administration significantly sensitized Cisplatin based chemotherapy in orthotopic liver cancer model. Down-regulation of DHFR may be one of the reasons for YQ23 sensitizing Cisplatin based chemotherapy. Real-time intravital imaging showed that YQ23 accumulated in the tumor tissue and maintained as long as 3 days in ectopic liver cancer model. The IVIS spectrum examination showed that YQ23 distributed mainly at liver and bladder within the first $\mathbf{3 6}$ hours after administration in orthotopic liver cancer model.

Conclusion: YQ23 treatment may be a potential therapeutic strategy to sensitize chemotherapy in HCC.

\section{INTRODUCTION}

Hepatocellular carcinoma (HCC) is the sixth most common cancer and ranks as high as third for cancerrelated deaths worldwide [1]. Liver transplantation is the effective treatment for selected HCC patients. Our previous study showed that severe hepatic ischemiareperfusion (IR) injury not only promotes tumor recurrence, but also induces chemoresistance in recurrent HCC after liver transplantation [2]. Recently, we found that the hemoglobin-based oxygen carrier"YQ23" significantly ameliorates hepatic IR injury and prevent 
tumor recurrence [3]. Therefore, investigation of the role of YQ23 in sensitization of chemotherapy in HCC may help for developing novel therapeutic strategy targeting at HCC resistance after liver transplantation.

Hypoxia is one of the major reasons to induce chemoresistance of HCC cells [4]. It has been reported that hypoxia could promote chemoresistance in HCC through hypoxia induced multidrug-resistance related gene, such as multidrug resistance transporter P-glycoprotein [5], MDR1 (Multi-Drug Resistance Gene 1), MRP1 (Multidrug Resistance-associated Protein 1) and LRP (Lung Resistance-related Protein) [6]. Hypoxia protects HCC cells from chemotherapy-induced apoptosis [7]. Moreover, HIF-1 $\alpha$ (Hypoxia-Inducible Factor 1-alpha) promotes hypoxia induced chemoresistance in HCC through up-regulation of WSB-1 (WD repeat and SOCS Box-containing protein 1) [8]. Nuclear translocation and activation of YAP (Yes-Associated Protein 1) also contributes to hypoxia induced chemoresistance in HCC [9]. Recent reports showed that Egr-1 (Early growth response protein 1) promotes chemoresistance in HCC through hypoxia induced autophagy [10]. As hypoxia is inevitable in liver transplantation and hypoxia induced chemoresistance could occur in recurrent HCC posttransplantation [2], attenuation of hypoxia environment of tumor cells using oxygen carrier may provide new insight for developing therapeutic strategy targeting at chemoresistance in $\mathrm{HCC}$, especially for recurrent $\mathrm{HCC}$ after liver transplantation.

YQ23 product is the stabilized non-polymeric crosslinked tetrameric hemoglobin $(65 \mathrm{kDa})$ with undetectable/ low level of dimeric hemoglobin (32 kDa), phospholipid, DNA impurities and protein impurities. The hemoglobinbased oxygen carrier was originally developed as an alternative strategy for erythrocytes transfusion $[11,12]$. It has been reported that the artificial oxygen carrier can effectively improve oxygenation in liver, kidney and other organs $[3,13,14]$. Our previous study showed that the hemoglobin-based oxygen carrier"YQ23" not only ameliorates hepatic ischemia-reperfusion (IR) injury, but also effectively reduced the incidence of tumor recurrence [3]. Our recent study showed that hepatic IR injury not only promotes tumor recurrence, but also induces chemoresistance in recurrent HCC after liver transplantation [2]. The role of YQ23 in sensitization of chemotherapy in HCC remains to be further investigated.

With the development of imaging technology, the modality of molecular intravital imaging currently enables us to directly see the tumor cells and molecules interaction in a live animal. Optical technique of functional imaging has well developed in clinical situation, including magnetic resonance imaging (MRI), positron emission tomography (PET) or computed tomography (CT). However, the major challenge in such technique is the limited penetration depth imposed by tissue turbidity, which avoids the possibility of utilizing high resolution microscope [15]. Here, we utilized a novel intravital imaging system using dorsal window chamber which could overcome such limitation. The intravital imaging of dorsal window chamber has been already applied in detection of vascularization with the advantages of longitudinal observation and high resolution in animal model [16]. The establishment of new platform of imaging would allow us to kinetically observe the drug delivery within tumor tissues with high resolution in a live animal.

In the present study, we aimed to explore the role of hemoglobin-based oxygen carrier "YQ23" in sensitization of Cisplatin based chemotherapy in HCC. We firstly studied the role of YQ23 in proliferation of HCC under the presence of Cisplatin using MTT and colony formation assay. Then, we examined the effect of YQ23 treatment combined with Cisplatin on tumor growth in orthotopic liver cancer model and further explore the underlying mechanism. After that, we investigated the delivery and distribution of YQ23 using real-time intravital imaging system. We hoped that our study could provide the evidences for using oxygen carrier YQ23 to sensitize Cisplatin based chemotherapy of HCC after liver transplantation.

\section{RESULTS}

\section{YQ23 significantly suppressed the proliferation of $\mathrm{HCC}$ cells under Cisplatin treatment in a dose and time dependent manner}

To examine whether YQ23 may sensitize Cisplatin based chemotherapy in HCC, MHCC97L cells were cultured under the presence of Cisplatin $(1 \mu \mathrm{g} / \mathrm{mL})$ and treated with different dosage of YQ23. The dosage of Cisplatin was determined by dose-response curve. We found that YQ23 significantly suppressed the proliferation of HCC cells under Cisplatin treatment in a dose dependent manner by MTT assay (Figure 1A). The peak effect of YQ23 was shown at the concentration of $0.2 \mathrm{~g}$ / dL. YQ23 significantly suppressed the proliferation of tumor cells at day 5 and 6 . It implied that the suppressive effect of YQ23 was more obvious at later phase. No significant effect was observed by YQ23 single treatment (Supplementary Figure 1). After that, we further examine the suppressive effect of YQ23 $(0.2 \mathrm{~g} / \mathrm{dL})$ under different concentration of Cisplatin (Figure 1B). We found that YQ23 could most significantly sensitize Cisplatin based chemotherapy at lower dosage of Cisplatin $(0.5 \mu \mathrm{g} / \mathrm{mL})$ at day 7 (Figure 1B). In order to examine the long time effect of YQ23 on tumor cells growth, MHCC97L cells were cultured under the combined treatment for 2 and 3 weeks. Again, we observed that YQ23 significantly suppressed the proliferation of $\mathrm{HCC}$ cells under Cisplatin in a dose dependent manner in colony formation assay (Figure 2A and 2B). 


\section{YQ23 significantly sensitized Cisplatin based chemotherapy in orthotopic xenograft liver cancer model}

To examine whether YQ23 may sensitize Cisplatin based chemotherapy in vivo, the nude mice orthotopic xenograft liver cancer model was established. Cisplatin and YQ23 were administrated into the mice once a week after tumor implantation. The experiments were performed in duplicate. We observed that YQ23 kinetically sensitized
Cisplatin based chemotherapy at week 5 and week 6 after tumor implantation (Figure 3A). No significant effect was observed by Cisplatin single treatment. The tumor volume was significantly lower by YQ23 treatment combined with Cisplatin therapy when the nude mice were sacrificed (Figure 3B). More necrotic areas were observed in combined treatment group by H\&E (Hematoxylin and eosin) staining (Figure 4A). More apoptotic cells were induced by combined treatment examined by TUNEL (Terminal deoxynucleotidyl transferase dUTP nick end labeling) assay (Figure 4B).

\section{A}

\section{Combined treatment}

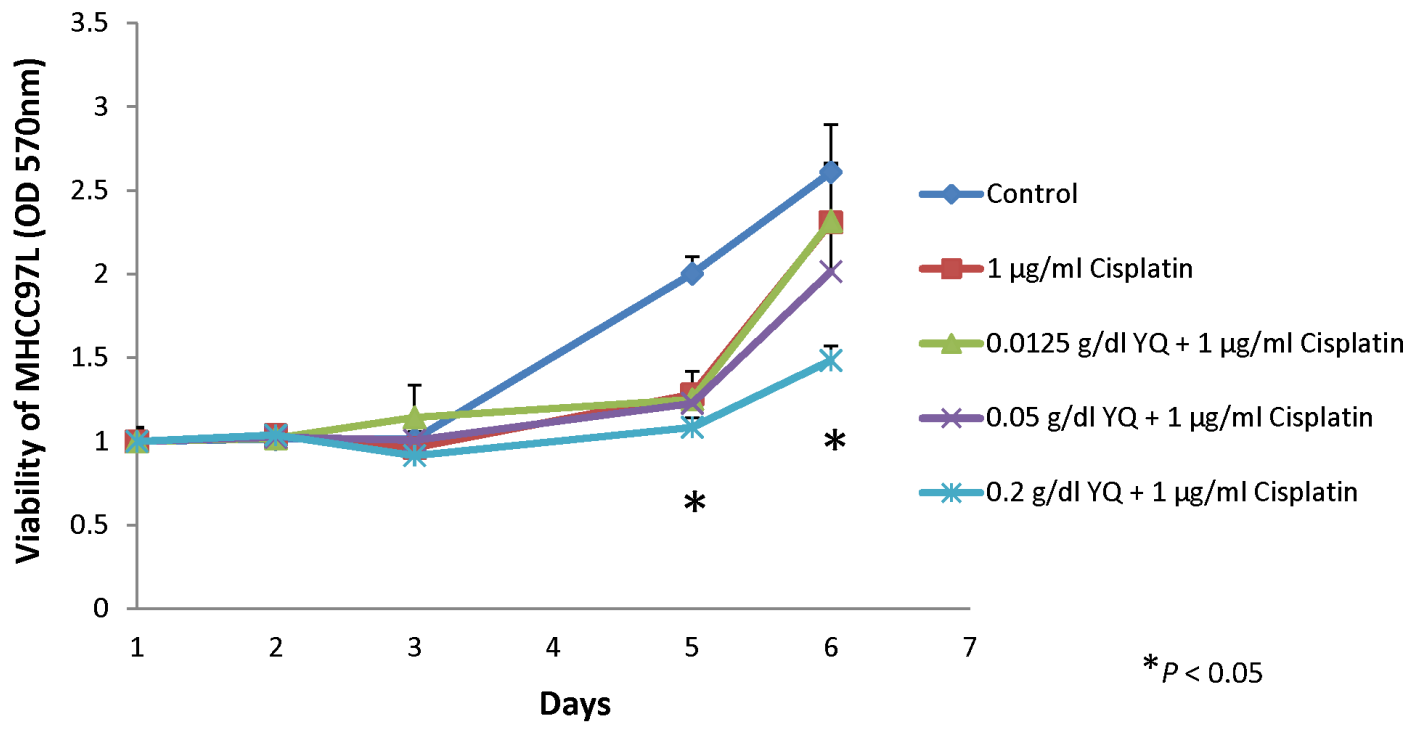

B

\section{Combined treatment}

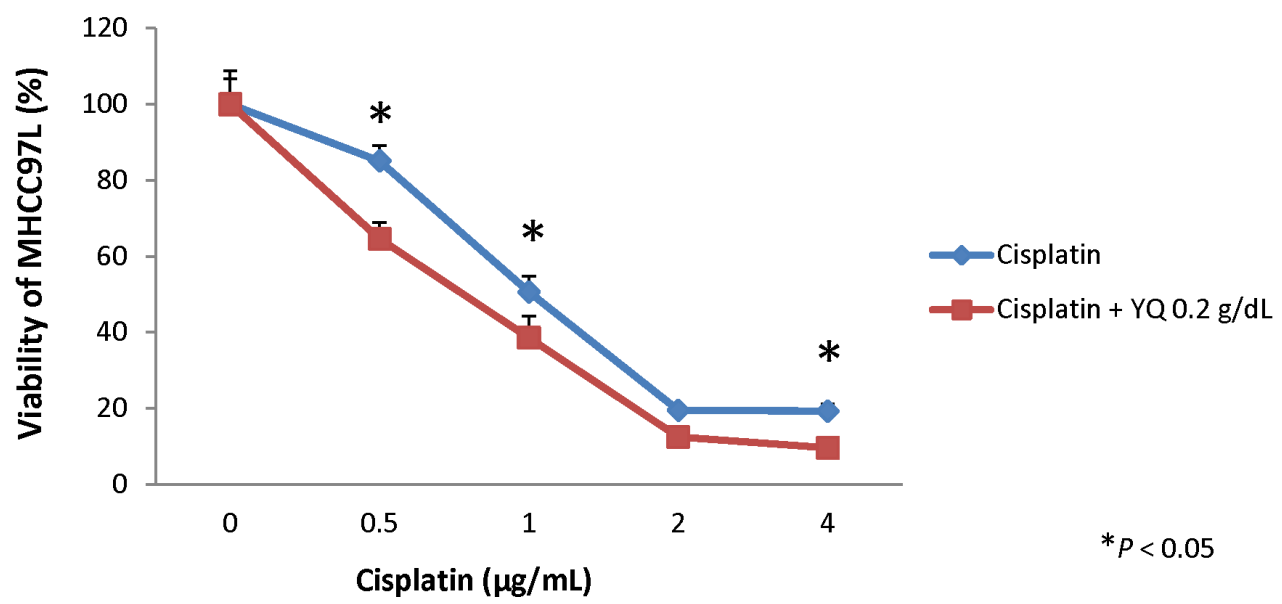

Figure 1: Oxygen carrier YQ23 significantly sensitized Cisplatin treatment by MTT assay in vitro. (A) YQ23 administration significantly suppressed the proliferation of HCC cells under Cisplatin treatment in a dose dependent manner. (B) YQ23 could most significantly sensitize Cisplatin treatment at lower dosage of Cisplatin at day 7. 
A
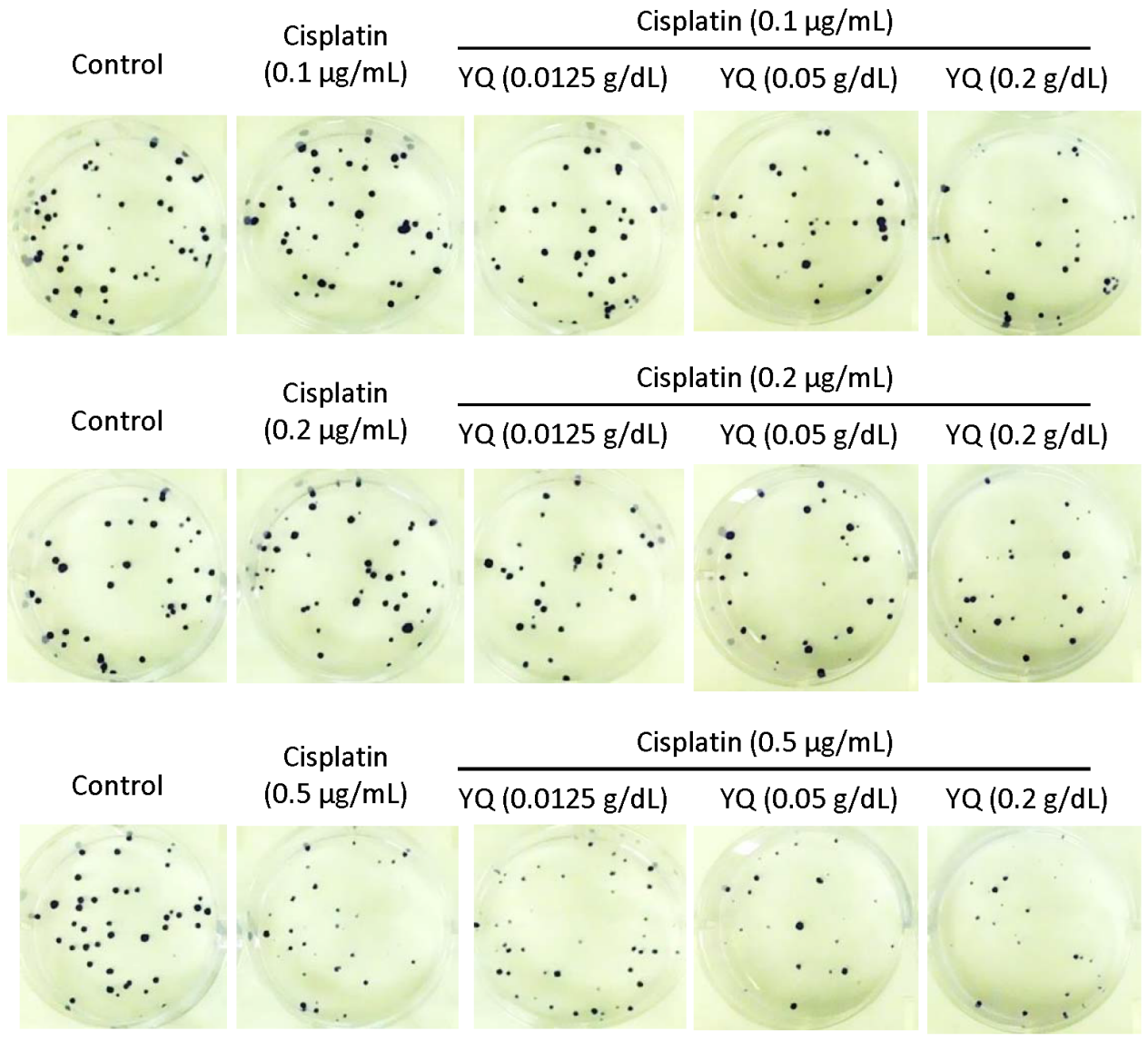

\section{B}
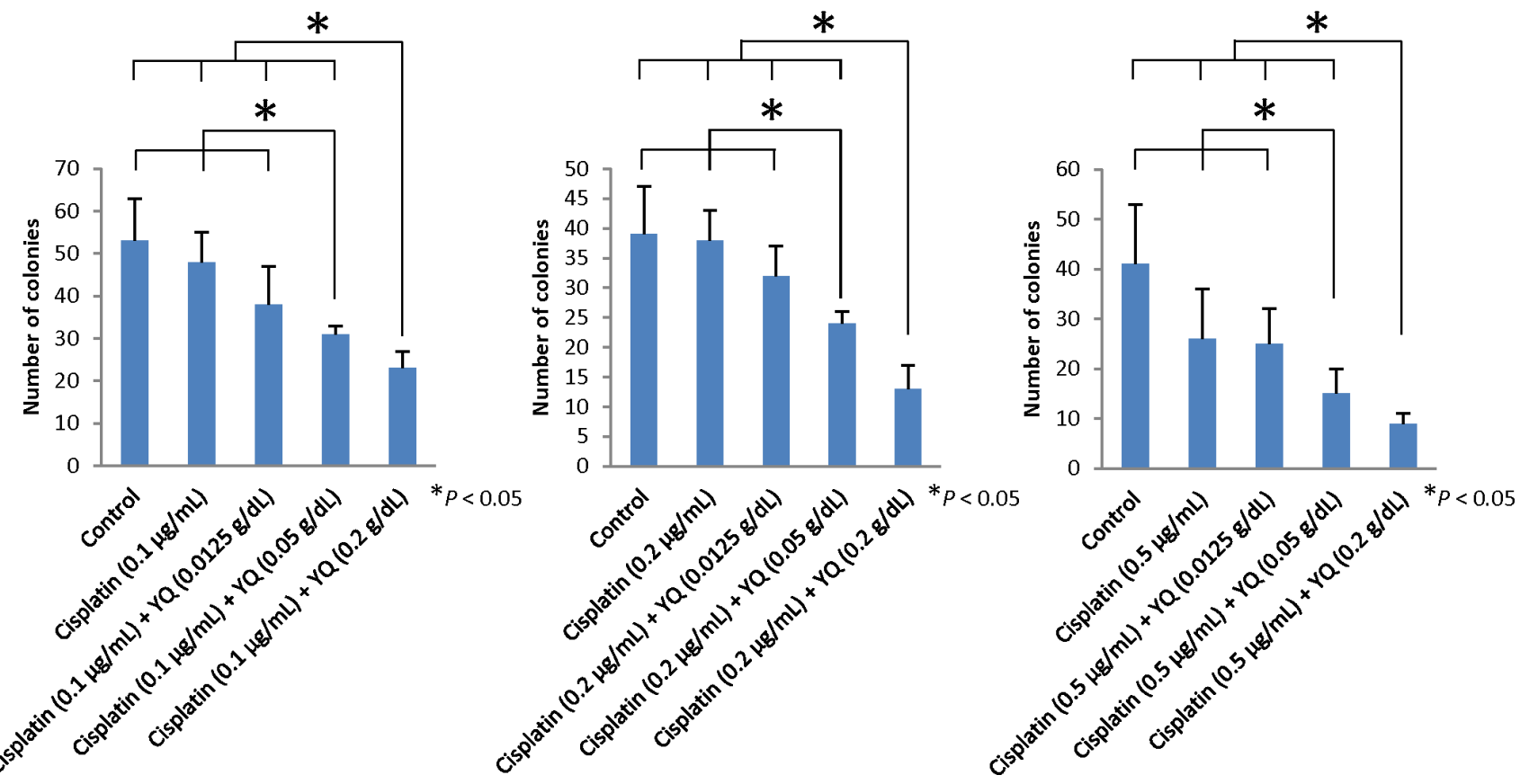

Figure 2: Oxygen carrier YQ23 significantly suppressed the colony formation of HCC cells under Cisplatin in a dose dependent manner. (A) Images of colony formation for 3 weeks. (B) Quantification and statistical analysis for colony formation. 
A

Control
Cisplatin
$(4 \mathrm{mg} / \mathrm{kg})$

Cisplatin $(4 \mathrm{mg} / \mathrm{kg})$
$+\mathrm{YQ}(0.4 \mathrm{~g} / \mathrm{kg})$

Week 5
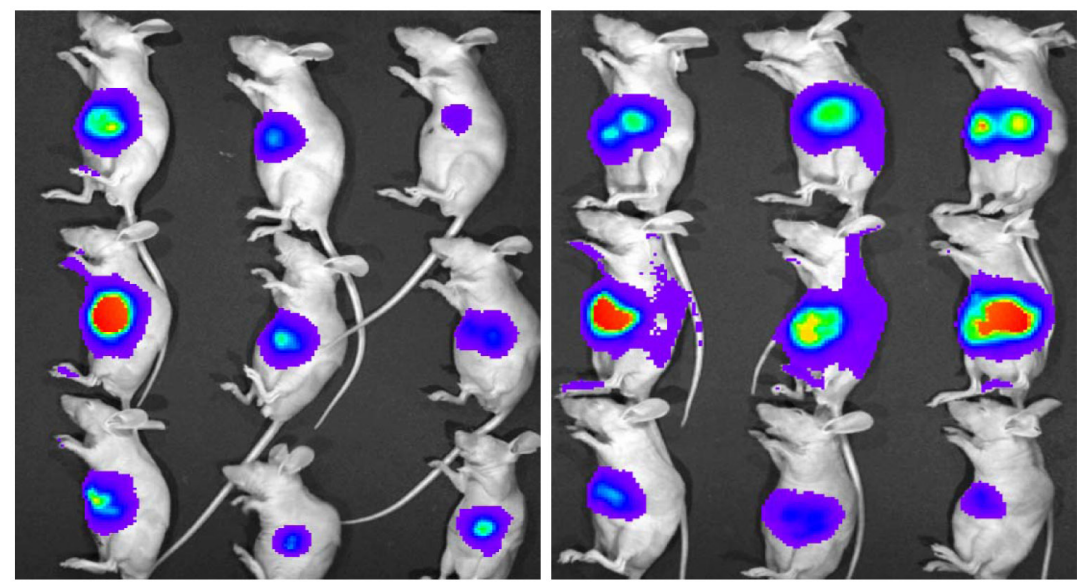

Week 6
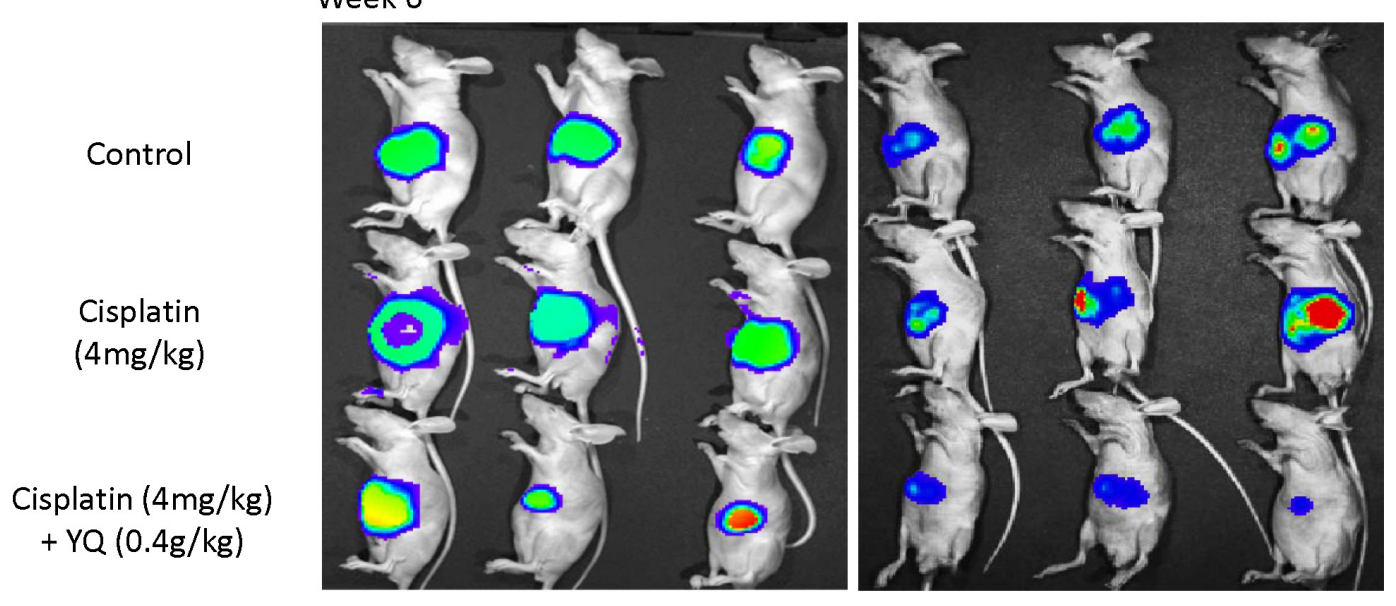

B

Cisplatin

$(4 \mathrm{mg} / \mathrm{kg})$

Cisplatin $(4 \mathrm{mg} / \mathrm{kg})$

$+Y Q(0.4 \mathrm{~g} / \mathrm{kg})$
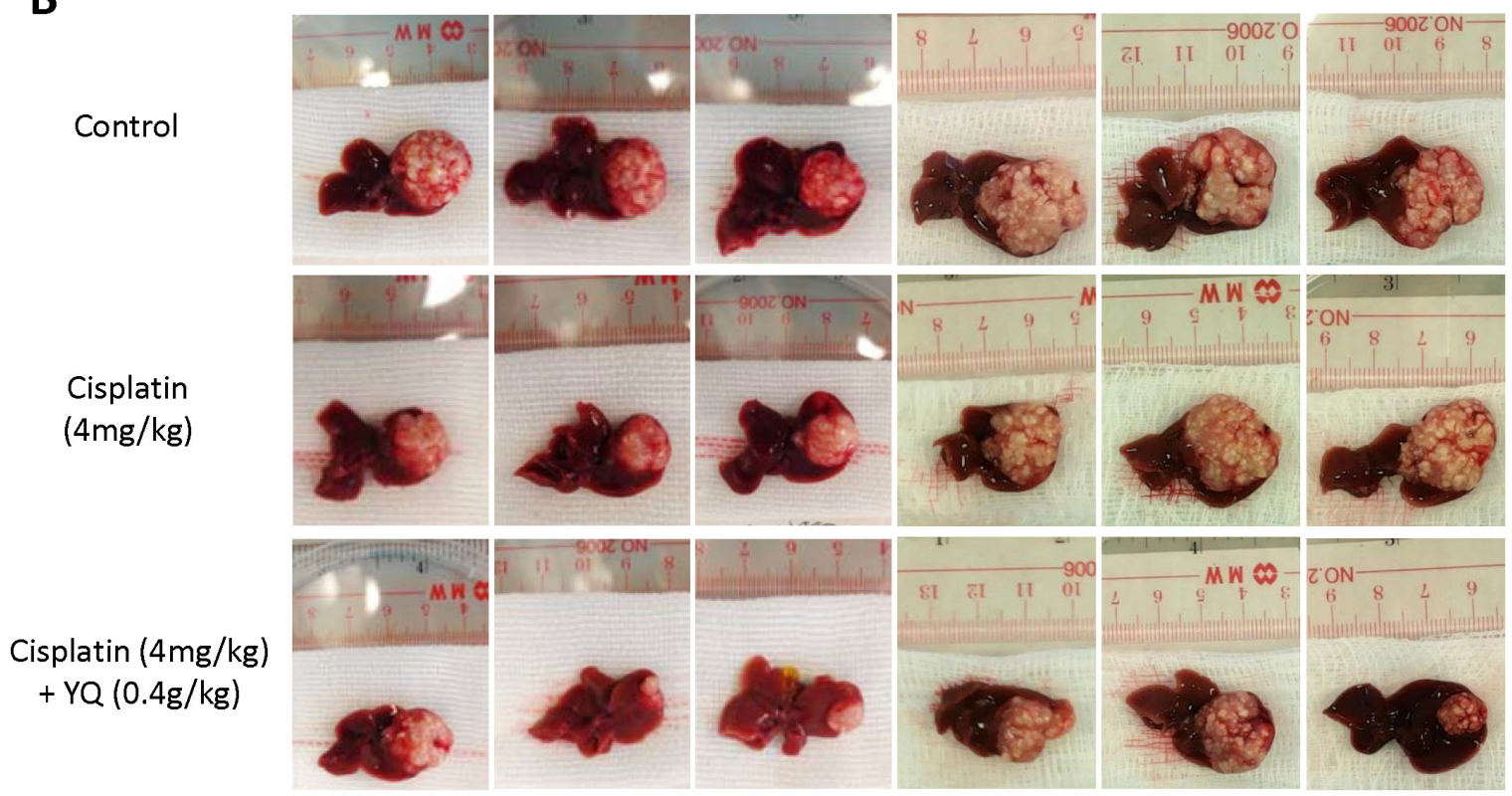

Figure 3: Oxygen carrier YQ23 significantly sensitized Cisplatin treatment in vivo. (A) YQ23 administration kinetically sensitized Cisplatin based chemotherapy in orthotopic xenograft liver cancer model. (B) The tumor volume was significantly lower by YQ23 treatment combined with Cisplatin therapy when the nude mice were sacrificed. 
A

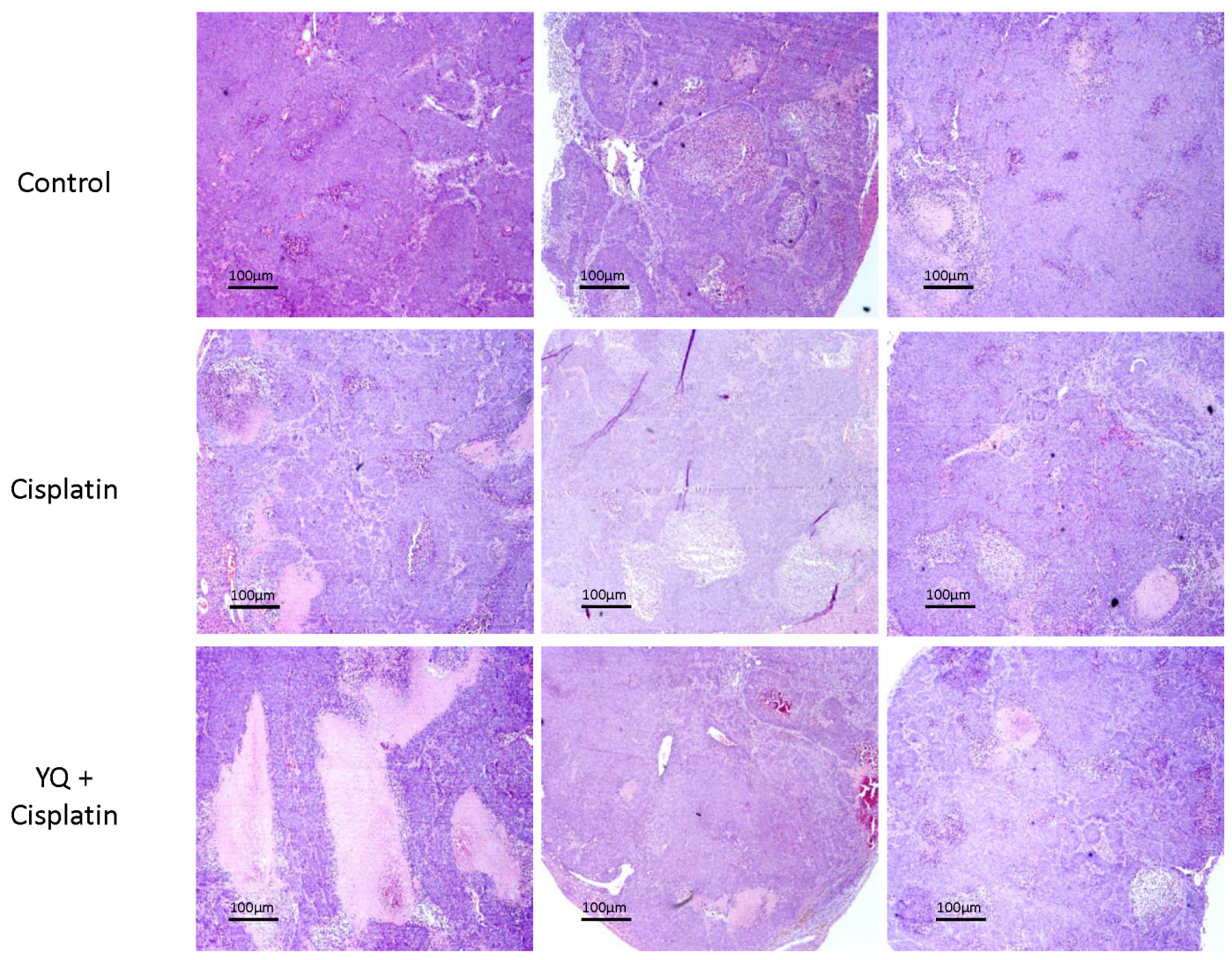

B

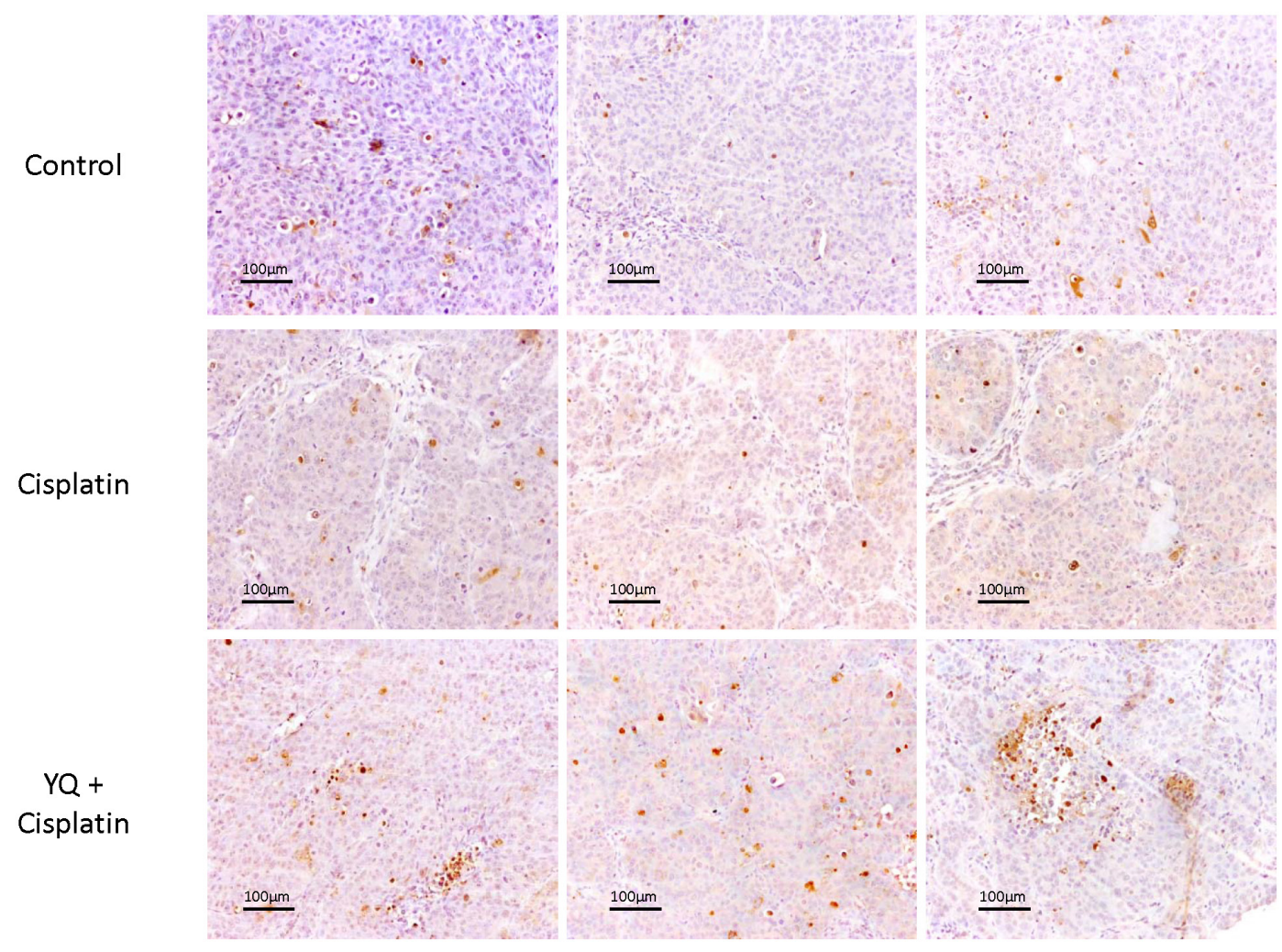

Figure 4: Oxygen carrier YQ23 combined with Cisplatin treatment induced more necrosis and apoptosis in tumor tissues. (A) More necrotic areas were observed in combined treatment group by H\&E staining (400×). (B) More apoptotic cells were induced by combined treatment examined by TUNEL assay (400×). 
Table 1: Differentially expressed drug resistance related genes in HCC cells after YQ treatment

\begin{tabular}{llll}
\hline Symbol & GenBank & UniGene & Description \\
\hline Down-regulated & & & \\
DHFR & NM_000791 & Hs.592364 & Dihydrofolate reductase \\
SULT1E1 & NM_005420 & Hs.479898 & Sulfotransferase family 1E, estrogen-preferring, member 1 \\
RARB & NM_000965 & Hs.654490 & Retinoic acid receptor, beta \\
CYP3A4 & NM_017460 & Hs.654391 & Cytochrome P450, family 3, subfamily A, polypeptide 4 \\
Up-regulated & & & \\
CYP1A1 & NM_000499 & Hs.72912 & Cytochrome P450, family 1, subfamily A, polypeptide 1 \\
CYP1A2 & NM_000761 & Hs.1361 & Cytochrome P450, family 1, subfamily A, polypeptide 2 \\
\hline
\end{tabular}

The 84 drug resistance related genes were involved in the PCR array. The genes encoding important enzymes for drug resistance (such as the P-glycoproteins), phase I metabolism (specifically the P450 family), and phase II metabolism (such as various covalent modification enzymes) were all represented on the array. Cancer-related genes involved in aspects of resistance are also included on the array such as DNA repair enzymes, cell cycle regulators, growth factor and hormone receptors and transcription factors.

\section{Down-regulation of dihydrofolate reductase (DHFR) may be one of the reasons for YQ23 sensitizing Cisplatin based chemotherapy}

In order to explore the mechanism of YQ23 sensitizing Cisplatin based chemotherapy, the drug resistance related pathways were further analyzed using RT $^{2}$ Profiler PCR array. Among 84 drug resistance related genes, using 2-fold as cutoff point, 4 down-regulated genes (DHFR, SULT1E1, RARB and CYP3A4) and 2 upregulated genes (CYP1A1 and CYP1A2) were identified in HCC cells after YQ23 treatment (Table 1, Figure 5A). After that, the expressions of these 6 potential gene candidates were further validated in orthotopic xenograft liver cancer model. We found that only DHFR was significantly downregulated upon YQ23 treatment combined with Cisplatin (Figure 5B). No significant change was found for the other 5 potential candidates. It implied that down-regulation of DHRF may be one of the reasons responsible for YQ23 sensitizing Cisplatin based chemotherapy.

\section{Real-time intravital imaging (Confocal) showed that YQ23 accumulated in the tumor tissue in ectopic xenograft liver cancer model using dorsal window chamber}

We further examine whether YQ23 could be delivered into the tumor tissues using intravital imaging system. The nude mice ectopic xenograft liver cancer model was established using dorsal window chamber (Figure 6A). Through the dorsal window chamber, we can kinetically observe the drug delivery and directly see the tumor cells in a live animal. Using the real-time intravital imaging system, we observed that YQ23 could be accumulated in the tumor tissues as early as 1 day after systemic administration (Figure 6B). Moreover, we found that YQ23 could be detected in the tumor tissues as long as 3 days after administration (Figure 6C).

Intravital imagine showed that fewer YQ23 were examined within tumor tissues compared with that around the tumor tissues (Figure 6B). There may be two explanations. On one hand, the newly formed blood vessels originated from peri-tumor region. Therefore, the concentration of YQ23 was higher around the tumor tissues after systemically administration. One the other hand, the blood pressure was relatively higher within the tumor tissues due to the aggressive growth pattern of tumor cells.

\section{The IVIS spectrum examination showed that YQ23 distributed mainly at liver and bladder within the first 36 hours after administration in orthotopic xenograft liver cancer model}

In order to examine the distribution of YQ23 after injection, the nude mice orthotopic xenograft liver cancer model was established. The labeled YQ23 were injected through tail vein. The IVIS spectrum examination showed that YQ23 distributed mainly at liver and bladder within first 36 hours after injection and gradually excreted through bladder afterwards (Figure 7A).

\section{Reconstructed 3D images showed that YQ23 distributed intracellularly in $\mathrm{HCC}$ cells}

In order to investigate whether YQ23 may directly penetrate into the HCC cells, the MHCC97L cells were cultured under the presence of YQ23 with different concentration. Under confocal microscope, we observed that YQ23 could be accumulated intracellularly in HCC cells as early as 1 day after administration (Figure 7B). 


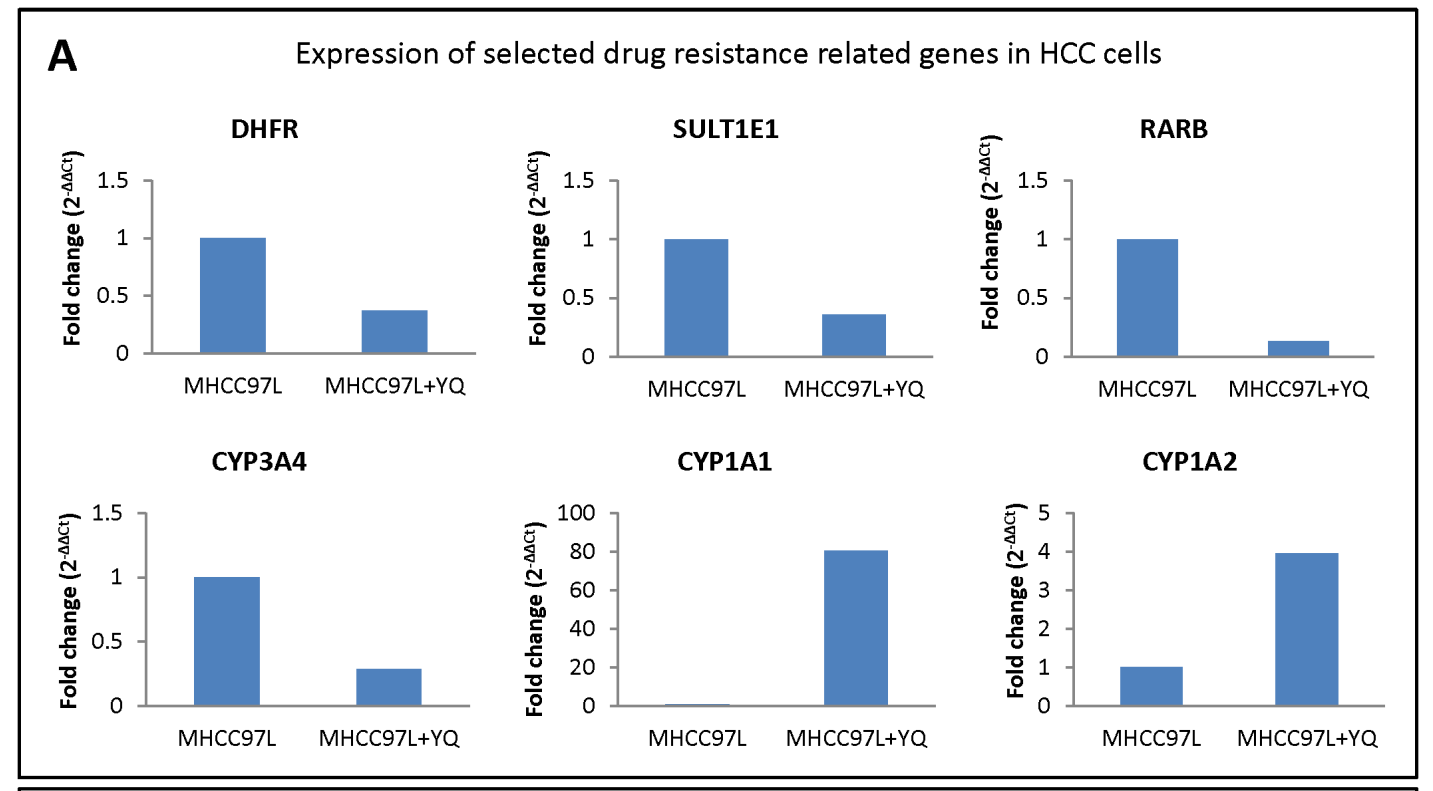

B Expression of selected drug resistance related genes in orthotopic liver cancer model
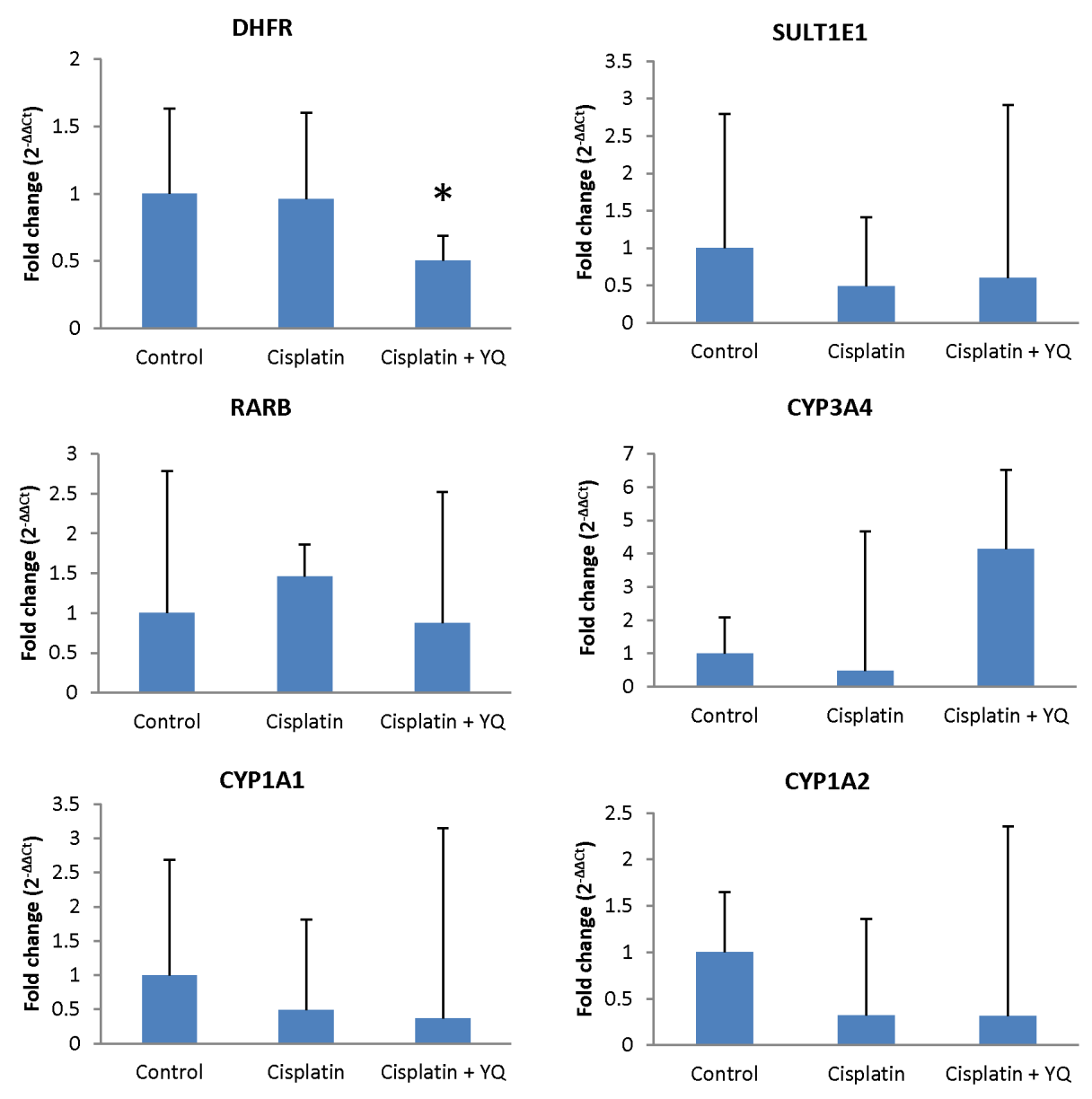

Figure 5: Down-regulation of dihydrofolate reductase (DHFR) may be one of the reasons for YQ23 sensitizing Cisplatin based chemotherapy. (A) RT2 Profiler PCR array showed that 4 down-regulated genes (DHFR, SULT1E1, RARB and CYP3A4) and 2 up-regulated genes (CYP1A1 and CYP1A2) were identified in HCC cells after YQ23 treatment. (B) Only DHFR was significantly downregulated upon YQ23 treatment combined with Cisplatin in orthotopic xenograft liver cancer model. ${ }^{*} P<0.05$. 
A

Establishment of nude mice ectopic xenograft liver cancer model with dorsal window chamber

B
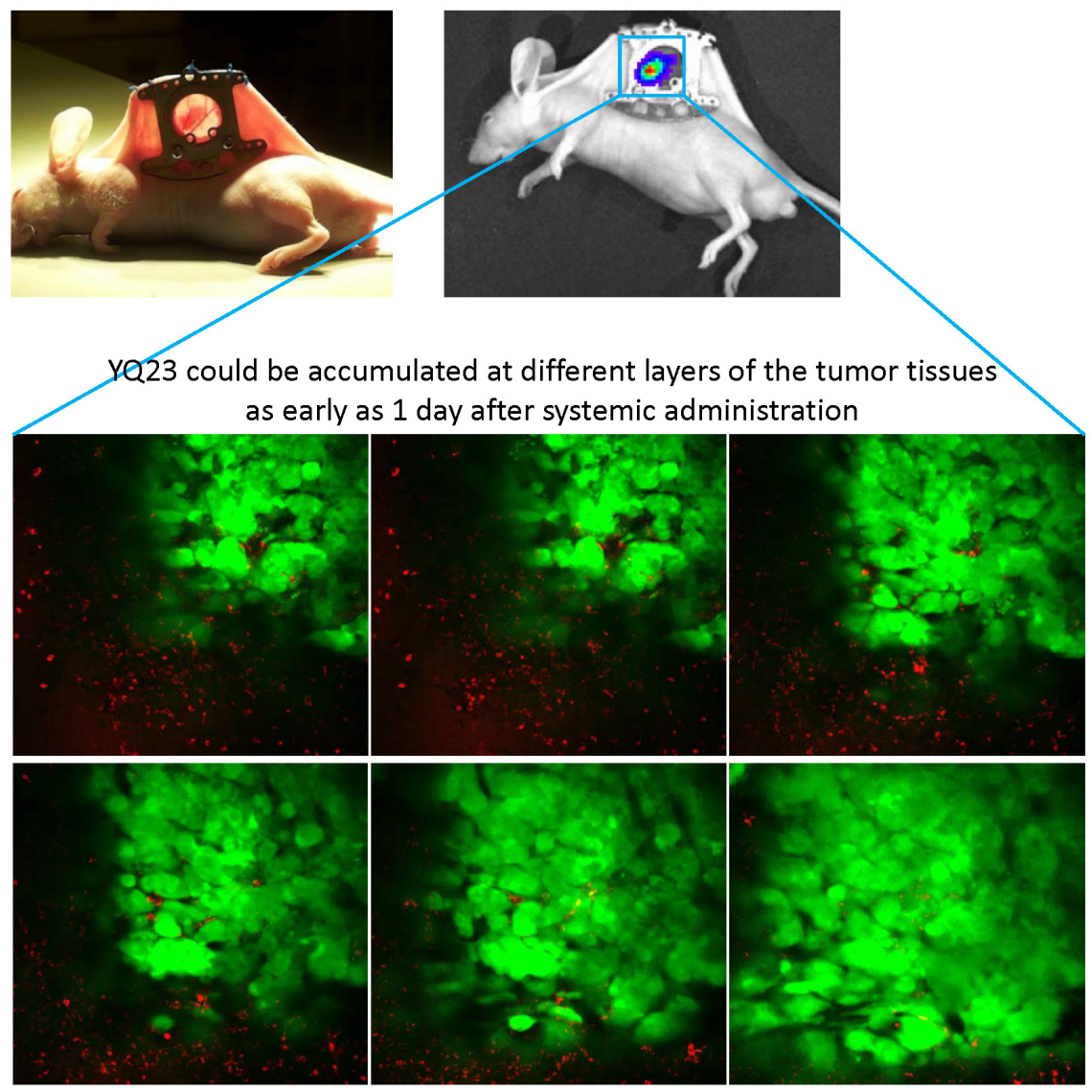

C

YQ23 could be maintained in the tumor tissues as long as 3 days after systemic administration

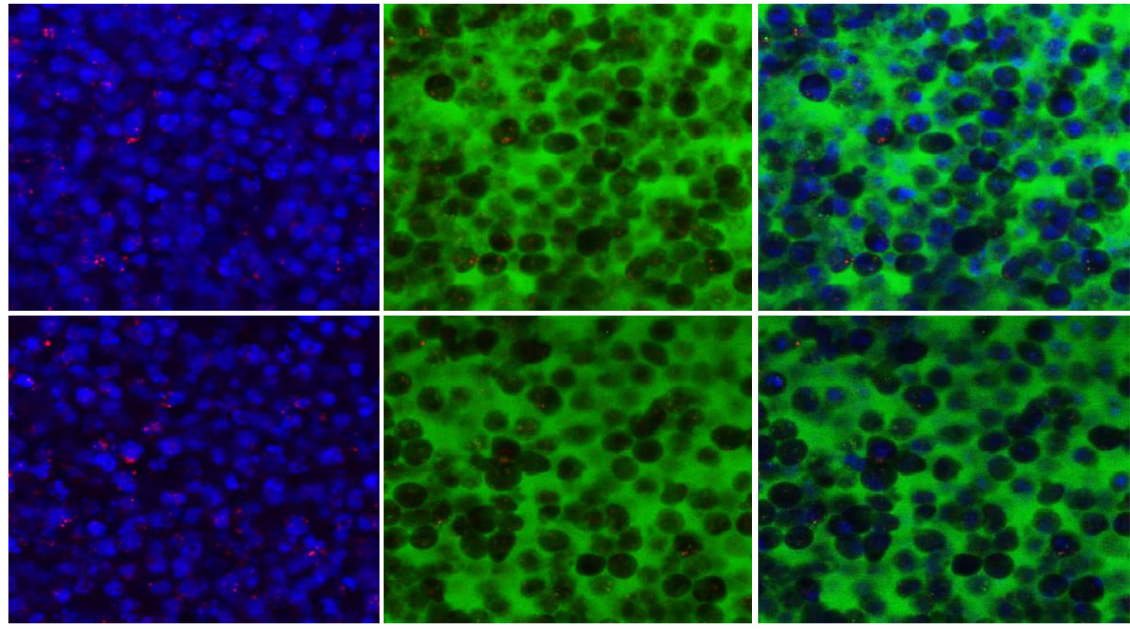

Nuclear (Hoechst33342)

Liver cancer (Cytoplasm, GFP)

YQ (Alexa Fluor 647)

Figure 6: Real-time intravital imaging (Confocal) showed that YQ23 accumulated in the tumor tissue in ectopic xenograft liver cancer model using dorsal window chamber. (A) Establishment of nude mice ectopic xenograft liver cancer model with dorsal window chamber. (B) YQ23 could be accumulated at different layers of the tumor tissues as early as 1 day after systemic administration. (C) YQ23 could be maintained in the tumor tissues as long as 3 days after administration. 
A The IVIS spectrum examination showed that YQ23 distributed mainly at liver and bladder within the first 36 hours after administration in orthotopic xenograft liver cancer model

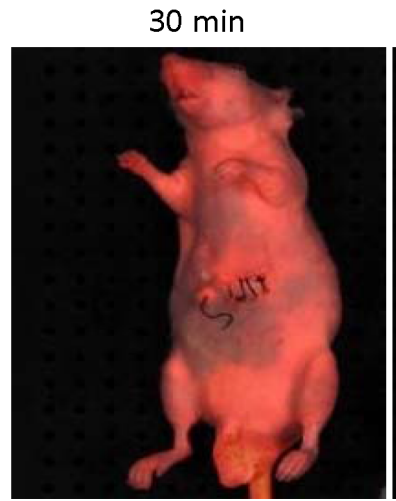

$36 \mathrm{~h}$

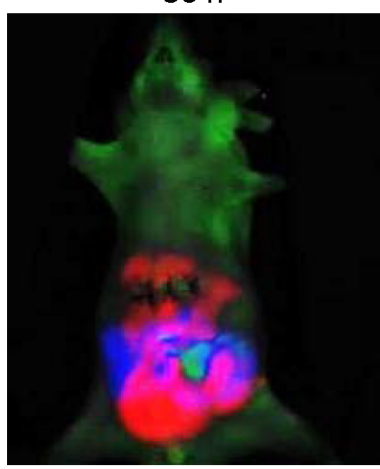

YQ (Alexa Fluor 647)
$3 \mathrm{~h}$

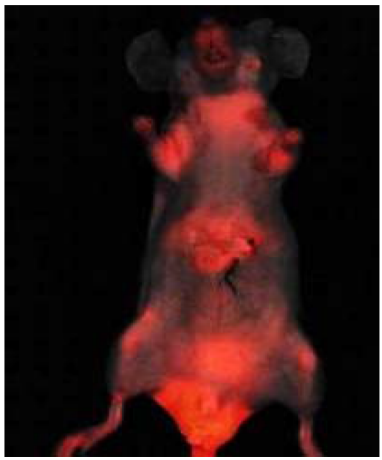

$60 \mathrm{~h}$

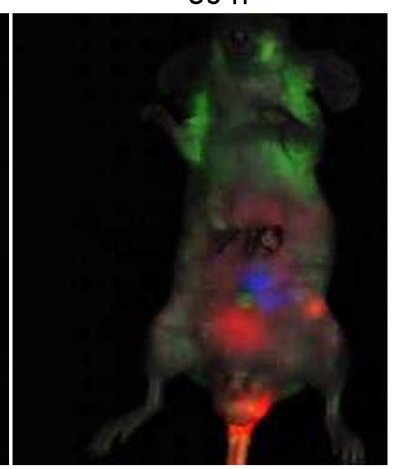

Tissue background
$6 \mathrm{~h}$

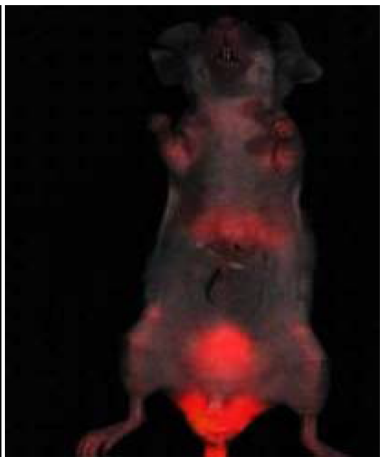

$84 \mathrm{~h}$

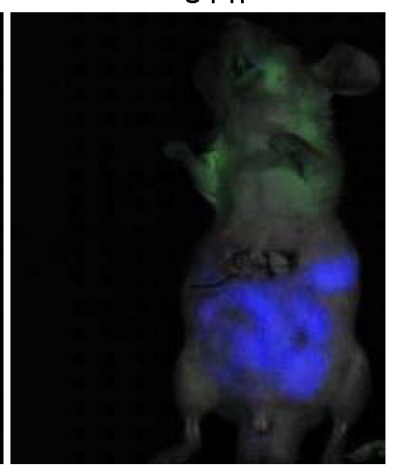

Food auto-florescence

B

Reconstructed 3D images showed that YQ23 distributed intracellularly in HCC cells

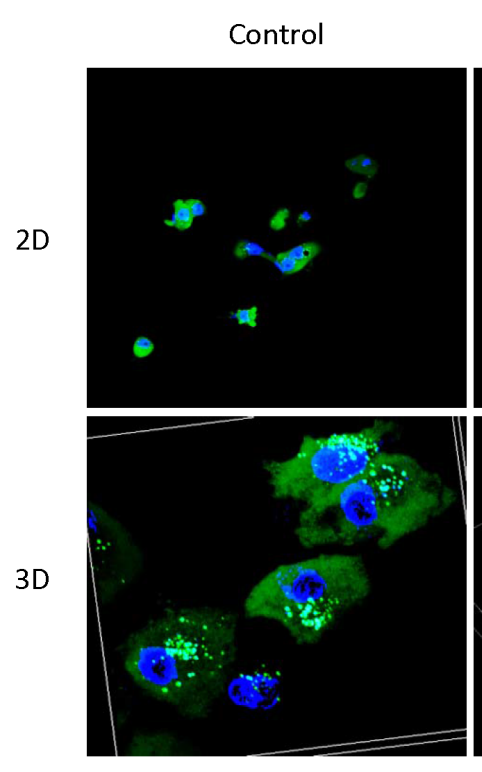

YQ (Alexa Flour 647)

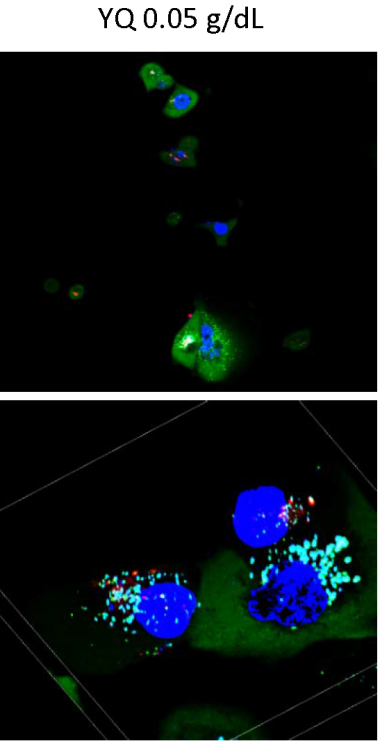

Liver cancer

(Cytoplasm, GFP)
$\mathrm{YQ} 0.2 \mathrm{~g} / \mathrm{dL}$

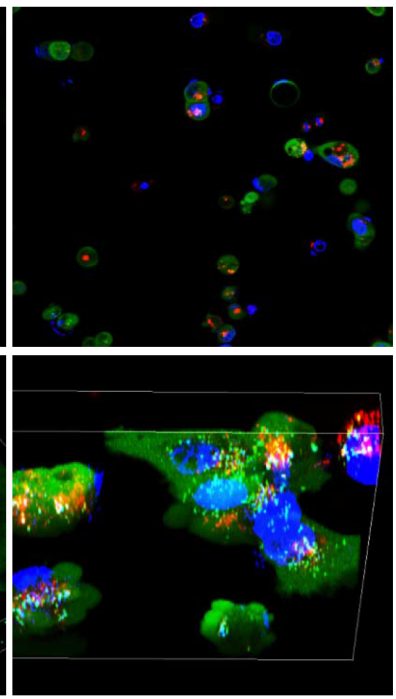

Nuclear (Hoechst33342)

Figure 7: Examination of YQ distribution in the whole body and tumor cells. (A) The IVIS spectrum examination showed that YQ23 distributed mainly at liver and bladder within first 36 hours after injection and gradually excreted through bladder afterwards. (B) YQ23 could be accumulated intracellularly in HCC cells as early as 1 day after administration. 


\section{DISCUSSION}

In the present study, we found that the novel oxygen carrier "YQ23" significantly sensitized Cisplatin based chemotherapy in HCC cells in vitro and in vivo. Furthermore, using real-time molecular intravital system, we observed that YQ23 could be delivered into the tumor tissue, accumulated intracellularly and maintained as long as 3 days after administration. We previously reported that YQ23 can effectively improve oxygenation in liver and ameliorated hepatic IR injury after liver surgery [3]. Our recent study also showed that severe hepatic IR injury induces chemoresistance in recurrent HCC after liver transplantation [2]. Based on the present and previous studies, the oxygen carrier YQ23 may be a "one stone for two birds" therapeutic strategy not only to ameliorate hepatic IR injury, but also to sensitize Cisplatin based chemotherapy in recurrent HCC after liver transplantation.

It has been reported that hemoglobin-based oxygen carrier enhances tumor oxygenation, especially in the low oxygen tension region within tumor tissue [17]. Recently, the artificial oxygen carrier has developed as a novel therapeutic strategy for tumor oxygenation and therefore, makes the tumor cells more susceptible to current cancer treatments [17]. Systemic administration of the hemoglobin-based oxygen carrier enhances tumor oxygenation and sensitizes radiotherapy in lung cancer [18]. A recent report showed that the artificial oxygen carrier significantly promotes oxygen supply within tumor and enhances the efficacy of radiotherapy in breast cancer [19]. The sensitization of radiotherapy by oxygen carrier is mediated through induction of apoptosis in bladder cancer [20]. However, the information about the role of oxygen carrier in sensitization of chemoresistance of tumor cells is rather limited. A recent report showed that the novel oxygen carrier YQ23 significantly enhances the drugsensitivity to 5-FU and Cisplatin treatment in esophageal squamous cell carcinoma (ESCC) [21]. Our previous study also showed that YQ23 promotes the efficacy of transarterial chemo-embolization (TACE) in a rat HCC model [14]. Based on our previous findings, we further explored in the present study the role of YQ23 in sensitization of chemoresistance in human HCC cells. We demonstrated, for the first time, YQ23 significantly sensitized Cisplatinbased chemotherapy in human HCC cells in vitro and in vivo. It has been proven that hemoglobin-based oxygen carrier transfusion is a safe therapeutic strategy [22, 23]. It may reduce the amount of chemotherapeutic agent in the combined treatment to achieve the similar therapeutic effect and therefore, may ameliorate the systemic sideeffects in chemotherapy.

It has been established that DHFR amplification is responsible for acquired methotrexate resistance [24, 25]. Moreover, the reports showed that only a low level of amplification of DHFR gene is sufficient to induce methotrexate resistance in the patients with leukemia [26]. Not only inducing methotrexate resistance, DHFR also plays an important role in Cisplatin resistance in ovarian cancer [27]. In our study, DHFR was identified as a downregulated gene in HCC cells upon YQ23 treatment and this finding was further validated in our animal model. This finding was also supported by the report that overexpression of DHFR is responsible for hypoxia induced chemoresistance [28]. Therefore, we provided the evidences that down-regulation of DHFR in transcription level may be one of the reasons for YQ23 sensitizing Cisplatin based chemotherapy. Investigations into the expression of translational level or protein function of DHFR in chemoresistance are worthwhile in the future study. In addition, it has been reported that hypoxia could induce Cisplatin resistance through activation of HIF- $\alpha$ in several types of cancer [29, 30]. However, HIF- $\alpha$ has not been identified as potential gene candidates in our current animal model. There might be two explanations. On one hand, the change of HIF- $\alpha$ expression is transient. It is difficult to be captured in animal study. On the other hand, the effect of HIF- $\alpha$ may be cell type specific.

The conventional measurement of delivery of oxygen carrier is examination of $\mathrm{pO}_{2}$ in the hypoxic tissues. Animal study for investigation of delivery of oxygen carrier always drew the conclusion based on the detection of $\mathrm{pO}_{2}$ at certain spots in the specific organ. However, the invasive technique is not an ideal measurement for observation of oxygen carrier delivery [31]. Hemorrhage is inevitable during detection and may influence $\mathrm{pO}_{2}$ dramatically [32]. Only detection at certain spots cannot indicate the distribution of oxygen carrier in the whole organ [31]. As the animal cannot tolerate anesthetization for a long time, it may avoid the possibility of kinetic observation for oxygen carrier delivery. Based on those limitations, a non-invasive technique for observation of drug delivery in a live animal is an urgent need. Currently available optical techniques of non-invasive imaging, such as MRI, PET and CT, are also limited by restricted penetration depth imposed by tissue turbidity, which avoids the possibility of utilizing high resolution microscope [15]. Real-time molecular intravital imaging with dorsal window chamber enables us to kinetically observe the delivery of oxygen carrier and directly see the tumor cells in a live animal. Utilizing the real-time intravital imaging system, we could clearly observe that YQ23 accumulated in the tumor tissue at day 1 after systemic administration and maintained as long as 3 days in ectopic xenograft liver cancer model using dorsal window chamber. Using IVIS spectrum examination, we also found that YQ23 distributed mainly at liver and bladder within the first 36 hours after administration and gradually excreted afterwards. It implied that systemic administration of YQ23 twice a week might be a practical protocol for the potential use for HCC patients in the future. 
In conclusion, we demonstrated that YQ23 administration significantly suppressed the proliferation of HCC cells under Cisplatin treatment in a dose and time dependent manner. Moreover, we found that the YQ23 administration significantly sensitized Cisplatin based chemotherapy in orthotopic xenograft liver cancer model. Down-regulation of DHFR may be one of the reasons for YQ23 sensitizing Cisplatin based chemotherapy. Realtime intravital imaging showed that YQ23 accumulated in the tumor tissue and maintained as long as 3 days in ectopic xenograft liver cancer model using dorsal window chamber. The IVIS spectrum examination showed that YQ23 distributed mainly at liver and bladder within the first 36 hours and gradually excreted afterwards in orthotopic xenograft liver cancer model. We hoped that our study could provide the evidences to explore novel therapeutic strategy using oxygen carrier YQ23 to sensitize Cisplatin based thermotherapy of HCC. The role of YQ23 in amelioration of multi-drug resistance of $\mathrm{HCC}$ is worthwhile for further study.

\section{MATERIALS AND METHODS}

\section{Cell culture}

The metastatic human liver cancer cell line MHCC97L was obtained from the Liver Cancer institute and Zhongshan Hospital of Fudan University, Shanghai, the People's Republic of China [33]. All the cell lines were cultured as previously described [34].

\section{Treatment regimen}

YQ23 products were obtained from New B Innovation Limited [3]. YQ23 product is the stabilized non-polymeric cross-linked tetrameric hemoglobin (65 $\mathrm{kDa}$ ) with undetectable/low level of dimeric hemoglobin (32 kDa), phospholipid, DNA impurities and protein impurities. The concentration of YQ product is $10 \mathrm{~g} / \mathrm{dL}$ and its $\mathrm{pH}$ range is $7.4-8.4$. The osmolality and viscosity (at $37^{\circ} \mathrm{C}$ ) are $250-340 \mathrm{mOsm} / \mathrm{kg}$ and $>0.9$ centipoise respectively. The p50 value is $\sim 40 \mathrm{mmHg}$. The information for YQ product is shown in patent no. US7, 932, $356 \mathrm{~B} 1$, US 8,048,856 B1 and PCT/US12/46130. For in vitro study, YQ23 was administrated at final concentration of 0.0125 , 0.05 and $0.2 \mathrm{~g} / \mathrm{dL}$. For in vivo study, YQ23 was injected through tail vein with the dosage of $0.4 \mathrm{~g} / \mathrm{kg}$. For all the study, the same volume of saline was administrated in the control group. For real-time molecular intravital imaging, The YQ23 was labeled with Alex-flour-647.

\section{3-(4, 5-dimethylthiazol-2-yl)-2, 5-diphenyltetrazolium bromide (MTT) assay and Colony formation assay}

In order to explore the proliferation rate of $\mathrm{HCC}$ cells, MTT and colony formation assay were performed as previously described [34, 35].

\section{Animal study}

Mice were housed in a standard animal laboratory with free activity and access to water and chow. They were kept under constant environment conditions with a $12 \mathrm{~h}$ light - dark cycle. Pentobarbitone sodium (40 mg/kg) was given intraperitoneally before any surgical procedure. Carprofen $(0.1 \mathrm{mg}$ in $100 \mathrm{ml}$ drinking water) were used to relieve the pain for the first 3 days after operation. All animal studies were conducted according to the animal ordinance set by the government of Hong Kong. The study had been licensed according to Animal (Control of Experiments) Ordinance Chapter 340 by the Department of Health, Hong Kong Special Administrative Region. (ref.: (11-632) in DH/HA\&P/8/2/3 Pt. 31).

\section{Nude mice ectopic xenograft liver cancer model}

MHCC97L cells $\left(1 \times 10^{6}\right.$ cells in 100 ul saline $)$ were injected subcutaneously into right flank of the nude mice (6-8weeks, male) under anaesthesia with intraperitoneal injection of pentobarbital. When the tumor size reached $2 \times 2 \mathrm{~mm}$, the dorsal window chamber was established for intravital imaging.

\section{Nude mice orthotopic xenograft liver cancer model}

When the subcutaneous tumors grew and reached $6 \mathrm{~mm} \times 6 \mathrm{~mm}$ in size, the animals were sacrificed by intraperitoneal injection of overdose pentobarbital. The tumor tissues were harvested and cut into $1-2 \mathrm{~mm}^{3}$ cubes. The tumor tissue cubes were then implanted into the left liver lobes of another group of mice under anaesthesia as described previously $[35,36]$. Five weeks after the tumor implantation, the animals were sacrificed for samples collection and further analysis. Six mice were recruited in each group.

\section{$\mathrm{RT}^{2}$ profiler PCR array}

The drug resistance related pathways were analyzed using $\mathrm{RT}^{2}$ Profiler PCR Array according to instruction manual (PAHS-004ZA, Qiagen). The Human Cancer Drug Resistance $\mathrm{RT}^{2}$ Profiler PCR Array profiles the expression of 84 genes involved in the body's response to chemotherapy. The differentially expressed gene candidates, using 2-fold as cutoff point, were identified in HCC cells (MHCC97L) after YQ $(0.2 \mathrm{~g} / \mathrm{dL})$ treatment for 2 days. After that, the expressions of the selected potential gene candidates were further validated in orthotopic liver cancer model.

\section{Real-time intravital imaging using dorsal window chamber}

The dorsal window chamber (DWC) consists of two titanium frames that marry together to form a saddle on the back of the nude mouse and is attached using spacers, bolts and fastening nuts. A 'chamber' is formed after a transparent glass cover slip placed onto the attached 
saddle covering the exposed fascia containing vessels and secured using a sterile removable ' $\mathrm{C}$ ' clip. The nude mice ectopic liver cancer model was established using liver cancer cells (MHCC97L). MHCC97L cells were labeled with fluorescence reporter (GFP) during transduction and then injected subcutaneously into the window chamber from the opposing side to the glass cover-slip. The YQ23 was labeled with Alex-flour-647. The distribution of YQ23 would be kinetically observed under CZ LSM 710 confocal system in a live animal.

\section{IVIS spectrum examination for distribution of YQ23}

In order to examine the distribution of YQ23 after injection, the nude mice orthotopic xenograft liver cancer model was established. The mice were fasted 12 hours before examination. The labeled YQ23-Alex-flour-647 was injected through tail vein. The distribution of YQ23 could be longitudinally observed by spectrum system (Perkin Elmer IVIS Spectrum). As the mice resumed food intake at later time points, the auto-florescence of food was distinguished through unmixing process.

\section{TUNEL assay and H\&E staining}

The Tunel assay and H\&E staining were performed as previously described [2, 35, 37, 38].

\section{Statistical analysis}

The Chi-square test was used to compare categorical data. Paired or unpaired $\mathrm{T}$ test were adopted to compare continuous variables. $P<0.05$ was considered as statistically significant. Calculation was made using SPSS computer software version 16 (SPSS Inc, Chicago, IL, USA).

\section{Abbreviations}

IR: ischemia-reperfusion; HCC: hepatocellular carcinoma; qRT-RCR: real time quantitative reverse transcription polymerize chain reaction; IHC: immunohistochemistry; HE: hematoxylin and eosin; MTT: 3 - (4, 5 - dimethylthiazol - 2 - yl) - 2, 5 diphenyltetrazolium bromide; DWC: The dorsal window chamber; DHFR: dihydrofolate reductase.

\section{Author contributions}

Xiang Qi, Kevin Tak Pan Ng, Yan Shao: acquisition of data; analysis and interpretation of data; drafting of the manuscript; Kwan Man, Chung Mau Lo, Bing L Wong, Sze Hang Lau: study concept and design, study supervision, obtained funding; Sui Yi Kwok, Chris KinWai Sun, Fei Chuen Tzang, Chang Xian Li, Wei Geng, Chang Chun Ling, Yuen Yuen Ma, Xiao Bing Liu, Hui
Liu, Jiang Liu, Wai Ho Yeung: technical or material support.

\section{ACKNOWLEDGMENTS}

The authors thank the New B Innovation Limited for its provision of YQ23.

\section{CONFLICTS OF INTEREST} Limited.

The YQ23 product is provided by New $\beta$ Innovation

\section{FUNDING}

This study was supported by The Industry collaborative research grant (260006681) of The University of Hong Kong, the Collaborative Research Fund (C7027-14G), HMRF (No.02132366), RGC General Research Funds (No.HKU775011M, 17115515, and 17115614) and National Science Foundation of China (NSFC) grants (No.81470903, 81572945 and 81320108015).

\section{REFERENCES}

1. Parkin DM, Bray F, Ferlay J, Pisani P. Global cancer statistics, 2002. CA Cancer J Clin. 2005; 55:74-108.

2. Geng W, Lo CM, Ng KT, Ling CC, Qi X, Li CX, Zhai Y, Liu XB, Ma YY, Man K. Interferon-gamma inducible protein 10 (IP10) induced cisplatin resistance of HCC after liver transplantation through ER stress signaling pathway. Oncotarget. 2015; 6:28042-28056. https://doi.org/10.18632/ oncotarget. 4832 .

3. Li CX, Wong BL, Ling CC, Ma YY, Shao Y, Geng W, Qi X, Lau SH, Kwok SY, Wei N, Tzang FC, Ng KT, Liu XB, et al. A novel oxygen carrier "YQ23" suppresses the liver tumor metastasis by decreasing circulating endothelial progenitor cells and regulatory T cells. BMC Cancer. 2014; 14:293.

4. Wu XZ, Xie GR, Chen D. Hypoxia and hepatocellular carcinoma: the therapeutic target for hepatocellular carcinoma. J Gastroenterol Hepatol. 2007; 22:1178-1182.

5. Wartenberg M, Ling FC, Muschen M, Klein F, Acker H, Gassmann M, Petrat K, Putz V, Hescheler J, Sauer H. Regulation of the multidrug resistance transporter P-glycoprotein in multicellular tumor spheroids by hypoxiainducible factor (HIF-1) and reactive oxygen species. FASEB J. 2003; 17:503-505.

6. Zhu H, Chen XP, Luo SF, Guan J, Zhang WG, Zhang $\mathrm{BX}$. Involvement of hypoxia-inducible factor-1-alpha in multidrug resistance induced by hypoxia in HepG2 cells. $\mathrm{J}$ Exp Clin Cancer Res. 2005; 24:565-574.

7. Piret JP, Cosse JP, Ninane N, Raes M, Michiels C. Hypoxia protects HepG2 cells against etoposide-induced apoptosis 
via a HIF-1-independent pathway. Exp Cell Res. 2006; 312:2908-2920

8. Tong Y, Li QG, Xing TY, Zhang M, Zhang JJ, Xia Q. HIF1 regulates WSB-1 expression to promote hypoxia-induced chemoresistance in hepatocellular carcinoma cells. FEBS Lett. 2013; 587:2530-2535.

9. Dai XY, Zhuang LH, Wang DD, Zhou TY, Chang LL, Gai RH, Zhu DF, Yang B, Zhu H, He QJ. Nuclear translocation and activation of YAP by hypoxia contributes to the chemoresistance of SN38 in hepatocellular carcinoma cells. Oncotarget. 2016; 7:6933-6947. https://doi.org/10.18632/ oncotarget.6903.

10. Peng WX, Xiong EM, Ge L, Wan YY, Zhang CL, Du $\mathrm{FY}, \mathrm{Xu} \mathrm{M}$, Bhat RA, Jin J, Gong AH. Egr-1 promotes hypoxia-induced autophagy to enhance chemo-resistance of hepatocellular carcinoma cells. Exp Cell Res. 2016; 340:62-70.

11. Pape A, Habler O. Alternatives to allogeneic blood transfusions. Best Pract Res Clin Anaesthesiol. 2007; 21:221-239.

12. Tsuchida E, Sou K, Nakagawa A, Sakai H, Komatsu T, Kobayashi K. Artificial oxygen carriers, hemoglobin vesicles and albumin-hemes, based on bioconjugate chemistry. Bioconjug Chem. 2009; 20:1419-1440.

13. Shen L, Qu R, Shi H, Huang F, An Y, Shi L. A biocompatible cobaltporphyrin-based complex micelle constructed via supramolecular assembly for oxygen transfer. Biomater Sci. 2016; 4:857-862.

14. Liu XB, Cheng Q, Geng W, Ling CC, Liu Y, Ng KT, Yam JW, Guan XY, Lo CM, Man K. Enhancement of cisplatinbased TACE by a hemoglobin-based oxygen carrier in an orthotopic rat HCC model. Artif Cells Nanomed Biotechnol. 2014; 42:229-236.

15. Palmer GM, Fontanella AN, Shan S, Hanna G, Zhang G, Fraser CL, Dewhirst MW. In vivo optical molecular imaging and analysis in mice using dorsal window chamber models applied to hypoxia, vasculature and fluorescent reporters. Nat Protoc. 2011; 6:1355-1366.

16. Laschke MW, Vollmar B, Menger MD. The dorsal skinfold chamber: window into the dynamic interaction of biomaterials with their surrounding host tissue. Eur Cell Mater. 2011; 22:147-164; discussion 164-147.

17. Gundersen SI, Palmer AF. Hemoglobin-based oxygen carrier enhanced tumor oxygenation: a novel strategy for cancer therapy. Biotechnol Prog. 2008; 24:1353-1364.

18. Yamamoto M, Izumi Y, Horinouchi H, Teramura Y, Sakai H, Kohno M, Watanabe M, Kawamura M, Adachi T, Ikeda E, Takeoka S, Tsuchida E, Kobayashi K. Systemic administration of hemoglobin vesicle elevates tumor tissue oxygen tension and modifies tumor response to irradiation. J Surg Res. 2009; 151:48-54.

19. Song G, Liang C, Yi X, Zhao Q, Cheng L, Yang K, Liu Z. Perfluorocarbon-loaded hollow Bi2 Se3 nanoparticles for timely supply of oxygen under near-infrared light to enhance the radiotherapy of cancer. Adv Mater. 2016; 28:2716-2723.

20. Kamuhabwa AR, Huygens A, Roskams T, De Witte PA. Enhancing the photodynamic effect of hypericin in human bladder transitional cell carcinoma spheroids by the use of the oxygen carrier, perfluorodecalin. Int J Oncol. 2006; 28:775-780.

21. Lee NP, Chan KT, Choi MY, Lam HY, Tung LN, Tzang FC, Han H, Lam IP, Kwok SY, Lau SH, Man C, Tong DK, Wong BL, Law S. Oxygen carrier YQ23 can enhance the chemotherapeutic drug responses of chemoresistant esophageal tumor xenografts. Cancer Chemother Pharmacol. 2015; 76:1199-1207.

22. Van Hemelrijck J, Levien LJ, Veeckman L, Pitman A, Zafirelis Z, Standl T. A safety and efficacy evaluation of hemoglobin-based oxygen carrier HBOC-201 in a randomized, multicenter red blood cell controlled trial in noncardiac surgery patients. Anesth Analg. 2014; 119:766-776.

23. Mozzarelli A, Ronda L, Faggiano S, Bettati S, Bruno S. Haemoglobin-based oxygen carriers: research and reality towards an alternative to blood transfusions. Blood Transfus. 2010; 8:s59-68.

24. Schimke RT. Gene amplification in cultured cells. J Biol Chem. 1988; 263:5989-5992.

25. Banerjee D, Mayer-Kuckuk P, Capiaux G, Budak-Alpdogan T, Gorlick R, Bertino JR. Novel aspects of resistance to drugs targeted to dihydrofolate reductase and thymidylate synthase. Biochim Biophys Acta. 2002; 1587:164-173.

26. Schweitzer BI, Dicker AP, Bertino JR. Dihydrofolate reductase as a therapeutic target. FASEB J. 1990; 4:2441-2452.

27. Li Z, Wang Q, Zhang W, Yang Z, Li L. [Cisplatin resistant effects of dihydrofolate reductase gene expression up-regulation in epithelial ovarian cancer].[Article in Chinese]. Zhonghua fu chan ke za zhi. 2015; 50:854-860.

28. Rice GC, Hoy C, Schimke RT. Transient hypoxia enhances the frequency of dihydrofolate reductase gene amplification in Chinese hamster ovary cells. Proc Natl Acad Sci U S A. 1986; 83:5978-5982.

29. Hao J, Song X, Song B, Liu Y, Wei L, Wang X, Yu J. Effects of lentivirus-mediated HIF-1alpha knockdown on hypoxia-related cisplatin resistance and their dependence on p53 status in fibrosarcoma cells. Cancer Gene Ther. 2008; 15:449-455.

30. Song X, Liu X, Chi W, Liu Y, Wei L, Wang X, Yu J. Hypoxia-induced resistance to cisplatin and doxorubicin in non-small cell lung cancer is inhibited by silencing of HIF-1alpha gene. Cancer Chemother Pharmacol. 2006; 58:776-784.

31. Eich S, Schmalzlin E, Lohmannsroben HG. Distributed fiber optical sensing of oxygen with optical time domain reflectometry. Sensors. 2013; 13:7170-7183. 
32. Williams KB, Christmas AB, Heniford BT, Sing RF, Messick J. Arterial vs venous blood gas differences during hemorrhagic shock. World J Crit Care Med. 2014; 3:55-60.

33. Li Y, Tang ZY, Ye SL, Liu YK, Chen J, Xue Q, Gao DM, Bao WH. Establishment of cell clones with different metastatic potential from the metastatic hepatocellular carcinoma cell line MHCC97. World J Gastroenterol. 2001; 7:630-636.

34. Geng W, Ng KT, Sun CK, Yau WL, Liu XB, Cheng Q, Poon RT, Lo CM, Man K, Fan ST. The role of proline rich tyrosine kinase 2 (Pyk2) on cisplatin resistance in hepatocellular carcinoma. PLoS One. 2011; 6:e27362.

35. Qi X, Ng KT, Lian QZ, Liu XB, Li CX, Geng W, Ling CC, Ma YY, Yeung WH, Tu WW, Fan ST, Lo CM, Man K. Clinical significance and therapeutic value of glutathione peroxidase $3(\mathrm{GPx} 3)$ in hepatocellular carcinoma. Oncotarget. 2014; 5:11103-11120. https://doi.org/10.18632/ oncotarget. 2549 .
36. Man K, Ng KT, Xu A, Cheng Q, Lo CM, Xiao JW, Sun BS, Lim ZX, Cheung JS, Wu EX, Sun CK, Poon RT, Fan ST. Suppression of liver tumor growth and metastasis by adiponectin in nude mice through inhibition of tumor angiogenesis and downregulation of Rho kinase/IFNinducible protein 10/matrix metalloproteinase 9 signaling. Clin Cancer Res the American Association for Cancer Research. 2010; 16:967-977.

37. Ng KT, Lo CM, Guo DY, Qi X, Li CX, Geng W, Liu XB, Ling CC, Ma YY, Yeung WH, Shao Y, Poon RT, Fan ST, Man K. Identification of transmembrane protein 98 as a novel chemoresistance-conferring gene in hepatocellular carcinoma. Mol Cancer Thers. 2014; 13:1285-1297.

38. Yeung OW, Lo CM, Ling CC, Qi X, Geng W, Li CX, Ng KT, Forbes SJ, Guan XY, Poon RT, Fan ST, Man K. Alternatively activated (M2) macrophages promote tumour growth and invasiveness in hepatocellular carcinoma. J Hepatol. 2015; 62:607-616. 